\title{
Clinical effect of health education intervention in chronic gastritis nursing.
}

\author{
Guo-Xing Yang ${ }^{1}$, Jun Zhang ${ }^{2 *}$ \\ ${ }^{1}$ Department of Senile Gastroenterology, Sichuan Academy of Medical Sciences and Sichuan Provincial People's \\ Hospital, Chengdu, Sichuan, PR China \\ ${ }^{2}$ Department of General Surgery, The Sixth People's Hospital of Chengdu, Chengdu, Sichuan, PR China
}

\begin{abstract}
Objective: This study aims to investigate the clinical effect of health education intervention in chronic gastritis nursing.

Methods: A total of 142 patients with chronic gastritis in our hospital from February 2016 to June 2017 were selected. They were divided into the control and research groups by odd and even numbers, with 71 patients for each group. The control group received conventional therapy and routine nursing, whereas the research group was offered with extra health education based on the control group. The two groups were compared in terms of related disease knowledge, nursing efficiency, nursing satisfaction, and nursing quality.

Results: Significant differences in psychological status, sleep quality, exercise training, and daily diet were found between the two groups $(\mathbf{P}<\mathbf{0 . 0 5})$. Compared with the control group, the research group achieved better related disease knowledge and higher nursing satisfaction and total nursing efficiency $(\mathbf{P}<\mathbf{0 . 0 5})$.

Conclusion: Health education intervention not only could enhance disease knowledge and control of patients with chronic gastritis but also could improve nursing quality, clinical effect, and nursing satisfaction. Thus, it is worthy of further popularization in clinics.
\end{abstract}

Keywords: Health education intervention, Chronic gastritis, Clinical effect.

\section{Introduction}

Chronic gastritis, a clinical gastroenterological disease with a high incidence rate, is characterized by chronic inflammatory changes in the gastric mucosa due to different factors [1]. This disease features slow development, long course, high recurrence rate, and high treatment difficulty, thereby significantly affecting the physical health and quality of life of patients [2,3]. Given its complexity, the clinical pathogenesis of chronic gastritis remains unclear to date. Therefore, health education of patients and family members about the disease should be enhanced, and patients should follow a healthy lifestyle including reasonable diet during clinical therapy to avoid recurrence [4]. In this study, a comparative study was carried out on 142 patients with chronic gastritis in our hospital. Results are introduced in the following text.

\section{Information and Methods}

\section{General information}

In this study, 142 patients with chronic gastritis in our hospital from February 2016 to June 2017 were chosen and divided into the control and research groups by odd and even numbers.
Each group had 71 patients. The control group had 37 males and 34 females, with ages ranging from 27 to 69 (48.25 \pm 7.52). The duration of the disease was $1 \mathrm{y}$ for the shortest and 12 years for the longest $(6.51 \pm 2.42)$. Of the 71 patients in the control group, 7 had chronic hypertrophic gastritis, 28 had chronic superficial gastritis, 21 had chronic atrophic gastritis, and 15 had chronic erosive gastritis. The research group had 38 males and 33 females, with ages ranging from 26 to 70 (49.31 $\pm 7.46)$. The duration of the disease was $1 \mathrm{y}$ for the shortest and 11 years for the longest $(6.38 \pm 2.40)$. Of the 71 patients in the research group, 8 had chronic hypertrophic gastritis, 25 had chronic superficial gastritis, 22 had chronic atrophic gastritis, and 16 had chronic erosive gastritis. Statistical processing revealed no significant difference in the baseline data of all patients $(\mathrm{P}>0.05)$. That is, the research and control groups were comparable in general information.

\section{Methods}

Health education: Chronic gastritis is difficult to be cured and easy to relapse, and no ideal clinical effect can be achieved after long-term treatment. In general, nursing personnel carefully explain to patients and family members the development of the disease and the value and prognosis of 
treatment to improve their hopes of cure, confidence to longterm fight with the disease, and positive cooperation in treatment and nursing. Given their different knowledge levels and educational backgrounds, some patients could not comprehend the disease. Nursing personnel also maintain good communications with family members of patients to increase their knowledge of the disease and train them to reduce patient contacts with pathogenic factors. Considering the frequent occurrence of acid regurgitation and gastrectasia, nursing personnel introduce emergency measures to family members of patients. If these emergency measures fail to relieve symptoms, the patients are sent to the hospital immediately. Moreover, some patients, especially old ones with poor memory and young ones busy with work, easily forget to take medicine. Nursing personnel and family members thus supervise them in taking medicine on time and as prescribed to help them recover as soon as possible.

Daily nursing: Irregular or poor diet and Hp infection are the main causes of chronic gastritis. Unreasonable diet causes great damages to the gastric mucosa, resulting in unsatisfactory disease improvement or continuous worsening. Hence, nursing personnel ask patients to keep good hygienic and dietary habits, stop smoking, and have enough sleep and rest to relieve gastrointestinal burdens significantly. They guide patients to do some exercises if possible to increase immunity and improve physical conditions. However, the exercise duration and strength are controlled.

Psychological nursing intervention: Stomach discomfort affects the appetite of patients significantly, resulting in poor nutrient conditions. Patients easily become anxious, depressed, irritable, and passive. They suffer from a psychological burden and even lose hope for cure. With comprehensive knowledge on psychological problems and basic conditions of patients, nursing personnel make individual communication to relieve and improve their negative emotions as much as possible. They maintain good communications with patients and introduce successful cases to them to increase their hope for cure. Moreover, they communicate with family members and ask them to take good care of patients and encourage them to accept treatment positively.

\section{Observation indexes and evaluation of clinical indexes}

Related disease knowledge: patients' knowledge on pathogenesis, causes, treatment key, and attentions was evaluated by conducting a chronic gastritis questionnaire survey designed by the hospital. The total score was 100 and was divided into four levels: high knowledge (90-100 scores), basic knowledge (75-90 scores), relative knowledge (60-75 scores), and poor knowledge ( $<60$ scores).

Nursing satisfaction: Patients' satisfaction to operation skills, service level, and attitude of nursing personnel was assessed by using the designed questionnaire survey. The total score was 100 and was divided into three levels: very satisfactory $(>80$ scores), satisfactory (60-80 scores), and unsatisfactory $(<60$ scores).
Nursing quality: Psychological conditions, sleep quality, exercise conditions, and daily diet of patients were evaluated. Higher score represents higher nursing quality.

Nursing efficiency: Complete disappearance of clinical symptoms and physical signs after prognosis and normal gastric mucosa observation in gastroscopy were considered "significant efficiency." Obvious improvement of clinical symptoms and physical signs after prognosis and mucosal lesion disappearance $\geq 50 \%$ in gastroscopy were denoted as "efficiency." No distinct changes and even worsening of clinical symptoms and physical signs and mucosal lesion disappearance $<50 \%$ in gastroscopy were regarded as "inefficiency." The total nursing efficiency is the sum of significant efficiency and efficiency (\%).

\section{Statistical analysis}

SPSS20.0 was used for statistical processing and analysis of all involved data. Measurement data (nursing quality) and enumeration data (nursing satisfaction, related disease knowledge, and nursing efficiency) were expressed as $(\overline{\mathrm{x}} \pm \mathrm{S})$ and percentage $(\%)$, respectively. t-test and $\chi^{2}$-test were performed to compare differences between two groups. $\mathrm{P}<0.05$ was considered to indicate statistically significant difference.

\section{Results}

\section{Nursing efficiency}

Total nursing efficiencies of the control and research groups were compared. The nursing efficiency of the research group was significantly higher than that of the control group $(\mathrm{P}<0.05)$ (Table 1)

Table 1. Comparison of nursing efficiency between the control and research groups $(n(\%))$.

\begin{tabular}{lllll}
\hline Group & $\begin{array}{l}\text { Significant } \\
\text { efficiency }\end{array}$ & Efficiency & Inefficiency & $\begin{array}{l}\text { Total } \\
\text { efficiency }\end{array}$ \\
\hline Control $(n=71)$ & $34(41.9)$ & $26(36.6)$ & $11(15.5)$ & $60(84.5)$ \\
\hline $\begin{array}{l}\text { Research } \\
(n=71)\end{array}$ & $38(53.5)$ & $32(45.1)$ & $1(1.4)$ & $70(98.6)$ \\
\hline$X 2$ & & & 9.1026 \\
\hline$P$ & & & 0.0026 \\
\hline
\end{tabular}

\section{Nursing satisfaction}

The research group achieved significantly higher nursing satisfaction than the control group $(\mathrm{P}<0.05)$ (Table 2$)$.

Table 2. Comparison of nursing satisfaction between the control and research groups $(n(\%))$.

\begin{tabular}{lllll}
\hline Groups & $\begin{array}{l}\text { Very } \\
\text { satisfying }\end{array}$ & Satisfying & Unsatisfying & Satisfaction \\
\hline $\begin{array}{l}\text { Control } \\
(n=71)\end{array}$ & $38(53.5)$ & $23(32.4)$ & $10(14.1)$ & $61(85.9)$ \\
\hline
\end{tabular}




\begin{tabular}{|c|c|c|c|c|}
\hline $\begin{array}{l}\text { Research } \\
(n=71)\end{array}$ & $43(60.6)$ & $26(36.6)$ & $2(2.8)$ & $69(97.2)$ \\
\hline$x^{2}$ & & & & 5.8256 \\
\hline P & & & & 0.0158 \\
\hline
\end{tabular}

\section{Related disease knowledge}

The research group showed significantly greater knowledge about chronic gastritis compared with the control group $(\mathrm{P}<0.05)$ (Table 3).

Table 3. Comparison of related disease knowledge between the control and research groups $(n(\%))$.

\begin{tabular}{llllll}
\hline Group & $\begin{array}{l}\text { High } \\
\text { knowledge }\end{array}$ & $\begin{array}{l}\text { Basic } \\
\text { knowledge }\end{array}$ & $\begin{array}{l}\text { Relative } \\
\text { knowledge }\end{array}$ & $\begin{array}{l}\text { Poor } \\
\text { knowledge }\end{array}$ & $\begin{array}{l}\text { Knowledg } \\
\text { e rate }\end{array}$ \\
\hline $\begin{array}{l}\text { Research } \\
(n=71)\end{array}$ & $30(42.3)$ & $20(28.2)$ & $8(11.3)$ & $13(18.3)$ & $58(81.7)$ \\
\hline $\begin{array}{l}\text { Control } \\
(n=71)\end{array}$ & $38(53.5)$ & $25(35.2)$ & $5(7.0)$ & $3(4.2)$ & $68(95.8)$ \\
\hline$X^{2}$ & & & & & 7.0437 \\
\hline$P$ & & & & & 0.0080 \\
\hline
\end{tabular}

\section{Nursing quality}

The research group had significantly higher scores in psychological conditions, sleep quality, exercise conditions, and daily diet compared with the control group $(\mathrm{P}<0.05)$ (Table 4).

Table 4. Comparison of nursing quality between the control and research groups ( $\bar{x} \pm S$, scores).

\begin{tabular}{lllll}
\hline Group & $\begin{array}{l}\text { Psychologic } \\
\text { al conditions }\end{array}$ & Sleep quality & $\begin{array}{l}\text { Exercise } \\
\text { conditions }\end{array}$ & Daily diet \\
\hline $\begin{array}{l}\text { Control } \\
(n=71)\end{array}$ & $77.2 \pm 11.3$ & $75.5 \pm 13.4$ & $81.7 \pm 9.6$ & $89.1 \pm 11.3$ \\
\hline $\begin{array}{l}\text { Research } \\
(n=71)\end{array}$ & $84.5 \pm 16.2$ & $90.6 \pm 5.2$ & $93.8 \pm 4.5$ & $95.9 \pm 13.6$ \\
\hline$t$ & 3.1142 & 8.8519 & 9.6163 & 3.2404 \\
\hline$P$ & 0.0022 & 0.0000 & 0.0000 & 0.0015 \\
\hline
\end{tabular}

\section{Discussion}

Chronic gastritis is very common in clinics. Poor appetite of different degrees, epigastric pain, vomiting, and acid regurgitation are the main clinical symptoms of this disease [5]. Chronic gastritis can be divided into atrophic gastritis, superficial gastritis, and other types according to pathogenesis [6]. Autoimmune disease, poor dietary habits, medication or physiological factors, and Hp infection are the main causes of chronic gastritis [7]. According to related research and clinical practices, related disease knowledge and treatment compliance of patients directly affect clinical effect, recurrence rate, and prognosis.
Health education mainly helps patients to master disease theory, develop self-nursing ability, and stimulate potential cooperation ability and consciousness through illustrations and special lectures, aiming to improve clinical effect and nursing efficiency $[8,9]$. Health education intervention to patients based on routine nursing not only increases patients' knowledge about the disease but also improves their treatment compliance and self-nursing ability. It can improve the quality of life and prognosis of patients while increasing the clinical effect [10]. This study proved that the research group is significantly superior to the control group in terms of total nursing efficiency, nursing satisfaction, related disease knowledge and nursing quality $(\mathrm{P}<0.05)$. This finding is consistent with previous literature.

\section{Conclusion}

Most patients with chronic gastritis exhibit poor knowledge about and provide minimal attention to the disease, thus affecting their medication cooperation and treatment compliance directly and reducing the quality of life and overall clinical effect dramatically. Standard and systematic health education that enhances the cognition of patients should be provided to improve the total clinical effect on chronic gastritis. Health education intervention not only could help patients with chronic gastritis to gain related disease knowledge but also could improve nursing quality, clinical effect, and nursing satisfaction. Thus, it is worthy of further popularization in clinics.

\section{References}

1. Li L, Kong L, Song H. The therapeutic effect of zerumbone on chronic gastritis via antioxidant mechanisms. Exp Ther Med 2017; 14: 2505-2510.

2. Abudoukelimu M, Yan F, Lei L, Guo Y. Vemurafenib disrupted the metabolism of drugs treating chronic obstructive pulmonary diseases (COPD). Lat Am J Pharm 2017; 36: 1088-1091.

3. Xing J, Min L, Zhu S, Zhang H, Zhao Y, Li H, Zhang Z, Li $\mathrm{P}$, Zhang S. Factors associated with gastric adenocarcinoma and dysplasia in patients with chronic gastritis: a population-based study. Chin J Cancer Res 2017; 29: 341-350.

4. Min A. A case report of postpartum hemolytic uremic syndrome. Biomed Res India 2017; 28: 3808-3810.

5. Simanenkov VI, Vyalov SS. Chronic gastritis: Instructions for use of medications. Ter Arkh 2017; 89: 129-133.

6. Zhang HY, Wang M, Yu ZJ, Sun CY, Li ZQ, Wu SH. Analysis of short-term efficacy of pegylated interferon $\alpha-2 \mathrm{a}$ and interferon $\alpha-2 \mathrm{a}$ in the treatment for chronic hepatitis $\mathrm{C}$. Lat Am J Pharm 2015; 34: 1785-1790.

7. Yorita K, Iwasaki T, Uchita K, Kuroda N, Kojima K, Iwamura S, Tsutsumi Y, Ohno A, Kataoka H. Russell body gastritis with Dutcher bodies evaluated using magnification endoscopy. World J Gastrointest Endosc 2017; 9: 417-424. 
8. Harrison M, Burns CF, McGuinness M, Heslin J, Murphy NM. Influence of a health education intervention on physical activity and screen time in primary school children: switch off-get active. J Sci Med Sport 2006; 9: 388-394.

9. Guo N, Lin G. Effects of nonsurgical periodontal therapy on serum inflammatory factor levels in patients with chronic kidney disease and periodontitis. Biomed Res India 2017; 28: 3899-3902.

10. Janevic MR, Janz NK, Dodge JA, Lin X, Pan W. The role of choice in health education intervention trials: a review and case study. Soc Sci Med 2003; 56: 1581-1594.

\section{*Correspondence to}

Jun Zhang

Department of General Surgery

The Sixth People's Hospital of Chengdu

PR China

Email: jun_zhang666@yeah.net 